\title{
Sign Language Interpreting in Theatre: Using the Human Body to Create Pictures of the Human Soul
}

\author{
Michael Richardson \\ Heriot-Watt University, Edinburgh
}

This paper explores theatrical interpreting for Deaf spectators, a specialism that both blurs the separation between translation and interpreting, and replaces these potentials with a paradigm in which the translator's body is central to the production of the target text. Meaningful written translations of dramatic texts into sign language are not currently possible. For Deaf people to access Shakespeare or Molière in their own language usually means attending a sign language interpreted performance, a typically disappointing experience that fails to provide accessibility or to fulfil the potential of a dynamically equivalent theatrical translation. I argue that when such interpreting events fail, significant contributory factors are the challenges involved in producing such a target text and the insufficient embodiment of that text. The second of these factors suggests that the existing conference and community models of interpreting are insufficient in describing theatrical interpreting. I propose that a model drawn from Theatre Studies, namely psychophysical acting, might be more effective for conceptualizing theatrical interpreting. I also draw on theories from neurological research into the Mirror Neuron System to suggest that a highly visual and physical approach to performance (be that by actors or interpreters) is more effective in building a strong actor-spectator interaction than a performance in which meaning is conveyed by spoken words. Arguably this difference in language impact between signed and spoken is irrelevant to hearing audiences attending spoken language plays, but I suggest that for all theatre translators the implications are significant: it is not enough to create a literary translation as the target text; it is also essential to produce a text that suggests physicality. The aim should be the creation of a text which demands full expression through the body, the best picture of the human soul and the fundamental medium of theatre. 